Summary This paper is concerned with historical changes in domestic ventilation and vapour dissipation rates and the associated risk of dust mite colonisation. A controlled trial evaluated allergen and water vapour control measures on the level of house dust mite (HDM) Der pl allergen and indoor humidity, concurrently with changes in lung function in 54 subjects who completed the protocol. MHRV units reduced water moisture content in the active group by an average of $12 \%$ while HDM allergen reservoirs in carpets and beds were reduced by over $96 \%$. Self reported health status confirmed a significant clinical improvement in the active group. The study can form the basis for minimum winter ventilation rates that are likely to inhibit dust mite colonisation and activity in maritime/temperate climatic regions.

\title{
Domestic ventilation rates, indoor humidity and dust mite allergens - Are our homes causing the asthma pandemic?
}

\section{SG Howieson ${ }^{1}$ BArch DipArch MPhil A Lawson ${ }^{1}$ B.Eng, C McSharry ${ }^{2}$ BSc PhD G Morris $^{3}$ BSc PhD E McKenzie ${ }^{4}$ BSc MSc PhD and J Jackson ${ }^{1}$ BEng}

${ }^{1}$ Dept. of Architecture and Building Science, University of Strathclyde, Glasgow, UK

${ }^{2}$ Dept. of Immunology, Western Infirmary, Glasgow, UK

${ }^{3}$ Scottish Centre for Infection and Environmental Health, Glasgow, UK

${ }^{4}$ Dept. of Statistics, University of Strathclyde, Glasgow, UK

\section{List of symbols}

$\begin{array}{ll}\text { ach }^{-1} & \text { air change rate per hour } \\ \text { HDM } & \text { house dust mite } \\ \text { MHRV } & \text { mechanical heat recovery ventilation } \\ \text { Der pl } & \text { HDM allergenic protein } \\ \text { RH } & \text { relative humidity } \\ \text { ESPr } & \text { computer based integrated hygro-thermal modelling programme } \\ \text { Tao } & \text { intake air temp } \\ \text { Tei } & \text { extract air temp }\end{array}$

\section{Introduction}

Concurrent with the dramatic rise in the incidence of asthma during the latter part of the twentieth century, has been a fundamental change in the design, construction and use patterns of domestic buildings in the UK. In addition to legislative changes - such as increasing the thermal resistivity of the building fabric - a variety of trends have combined to make dwellings warmer and more humid; conditions in which the dust mite species Dermatophagoides pteronnysinus can thrive:

- The move away from solid fuel and the associated sealing of open fireplaces has reduced internal air change rates. 
- The proliferation of timber frame dwellings incorporating polythene vapour barriers and little thermal mass, has lead to increased diurnal temperature fluctuations and reduced vapour dissipation rates.

- The use of 'hard' internal surface finishes such as gypsum plaster - a material that is relatively impermeable to water vapour absorption/desorption - will have reduced water vapour transmission through the construction layers.

- The rising incidence of central heating systems is likely to have increased average whole house temperatures.

- Improving hygiene standards have increased water vapour production with showers in particular contributing to aerosol migration.

- Internal clothes drying (possibly due to changing female employment patterns) will have increased the internal moisture burden.

- Retrofit double-glazing replacing notoriously draughty steel and timber units will also have reduced fortuitous background ventilation (between 1991 and 1996 the percentage of dwellings in Scotland that had double-glazing increased from $36 \%$ to $\left.62 \%{ }^{(1)}\right)$.

- Fitted carpets and 'soft toys' also provide suitable micro-climates for the photophobic dust mite.

\section{Research questions}

- What is the scale of the historical reduction in domestic ventilation rates?

- What is the level of occupant exposure to dust mite allergens in dwelling types where ventilation rates are likely to be low?

- What allergen avoidance measures and winter ventilation rates are required to ensure allergen burdens are maintained below sensitisation thresholds?

- How can this best be achieved in relatively small modern dwellings?

\section{$3 \quad$ Methods - Simulating changes in domestic ventilation rates}

ESP-r is an integrated modelling tool for the simulation of thermal, visual and acoustic performance of buildings. Five traditional Scottish house-types were modelled to norm reference air change rates in a typical living room (volume, materials, window type, flues and vents) for a 48 hour winter period. By inputting a set amount of water vapour into the system, a mass flow calculation can estimate the rate of moisture diffusion.

\section{$4 \quad$ House type}

The Scottish House Condition survey ${ }^{(1)}$ defined housing in Scotland by type, style and construction date - each representing the respective percentage of the total housing stock $(2,232,000)$. The five main generic types viewed as most common to an epoch were taken to be: 


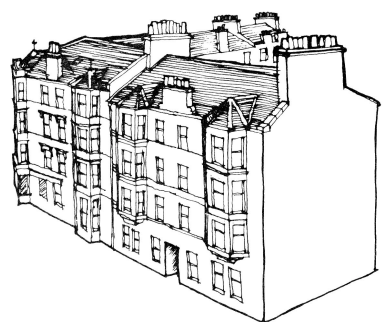

$19^{\text {th }}$ century tenement

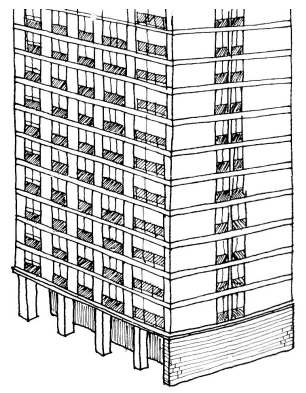

1970's multi storey
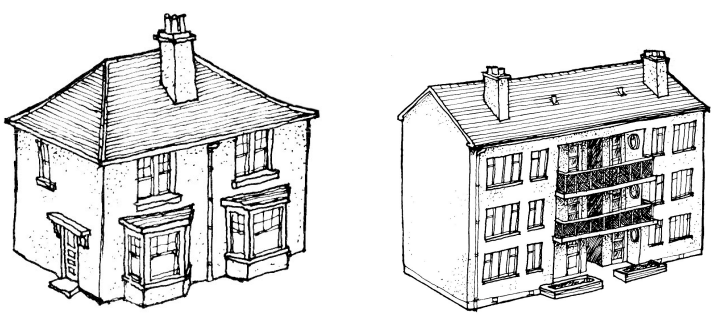

1930's semi-detached villa

1950's 3 storey tenement

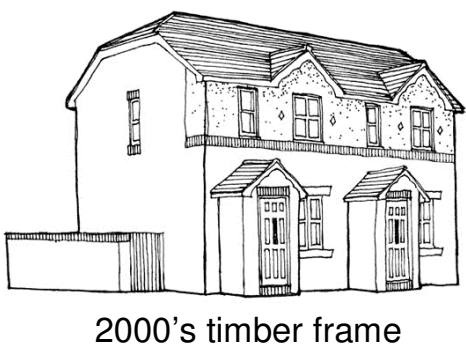

The main construction characteristics (volume, materials, heating system, flues, window type, crack length and trickle vents) were input as boundary conditions to the appropriate living room area. Simulations were then run to estimate air change rates during a $48 \mathrm{hr}$ mid-winter period (Jan $21^{\text {st }}-22^{\text {nd }}-$ composite climate file).

5

Results

\begin{tabular}{|l|l|l|l|l|l|}
\hline & Max $\left(\mathrm{ach}^{-1}\right)$ & Min. $\left(\mathrm{ach}^{-1}\right)$ & Ave. $\left(\mathrm{ach}^{-1}\right)$ & Vol. $\left(\mathrm{m}^{3}\right)$ & $\left(\mathrm{m}^{3} / \mathrm{h}\right)$ \\
\hline 1890 model & 2.15 & 0.78 & 1.66 & 83 & 138 \\
\hline 1936 model & 2.00 & 1.10 & 1.63 & 42 & 69 \\
\hline 1950 model & 1.03 & 0.63 & 0.835 & 37 & 31 \\
\hline 1970 model & 0.95 & 0.05 & 0.74 & 41 & 31 \\
\hline 2000 model & 0.63 & 0.23 & 0.45 & 33 & 15 \\
\hline
\end{tabular}

Table 1: ach $^{-1}$ for five living room models

\section{Discussion}

The most apparent difference between the 2 earlier and the 3 later models is the impact of the 'Clean Air Acts' on the presence and use of open flues. The air change rates for the 1890 and 1936 models at the chimney node within the airflow network were $12 \mathrm{ach}^{-1}$ and $10 \mathrm{ach}^{-1}$ respectively, providing evidence of the impact a flue has on the total room air change rate. An open fire would drive even greater air change rates, however, it was not possible to model such a scenario. In terms of volumetric air-flow, the late Victorian tenement has over nine times the rate of a contemporary timber frame model. Although the simulations are not necessarily attempting to criterion reference the models to produce an accurate facsimile of reality, the method can be 
defended as a technique to benchmark longitudinal trends and identify the influential factors (wind speed and direction) driving the system. The CIBSE ${ }^{(2)}$ recommendation of 8 litres/s per person for odour control equates to an air volume approaching $29 \mathrm{~m}^{3}$ per hour - almost twice the background air change rate of the twenty first century model. Such low rates in tight modern dwellings will cause odour and smoke to build during the winter -when windows are likely to remain closed - particularly when occupied by more than one person. The implications for vapour dissipation rates are of equal concern.

\section{$7 \quad$ Moisture dissipation rates}

Ventilation rates will have an important impact on water vapour diffusion. The following calculations are based on the mass flow rate of moisture, relative to the specific air change rates for each generic house type. It is assumed that the external air entering the living room through one inlet is mixing perfectly with the 'moist' air in the zone. The calculation is based solely on the living room as the test bed, with notional input and output boundary conditions for a typical winter day (incoming air temperature $4^{\circ} \mathrm{C}$, relative humidity $80 \%$, mixing ratio $4 \mathrm{~g} / \mathrm{kg}$, specific volume $0.7898 \mathrm{~m}^{3} / \mathrm{kg}$ ). The internal conditions are determined using the resultant data from the simulations: temperature $21^{\circ} \mathrm{C}$, air change rate, volume and flow rate specific to each model.

The outgoing air is set to a temperature of $21^{\circ} \mathrm{C}$ and a relative humidity of $70 \%$ (as this is the boundary condition for mould growth) and $50 \% \mathrm{RH}$, as this is the boundary condition for dust mite viability and colony activity.

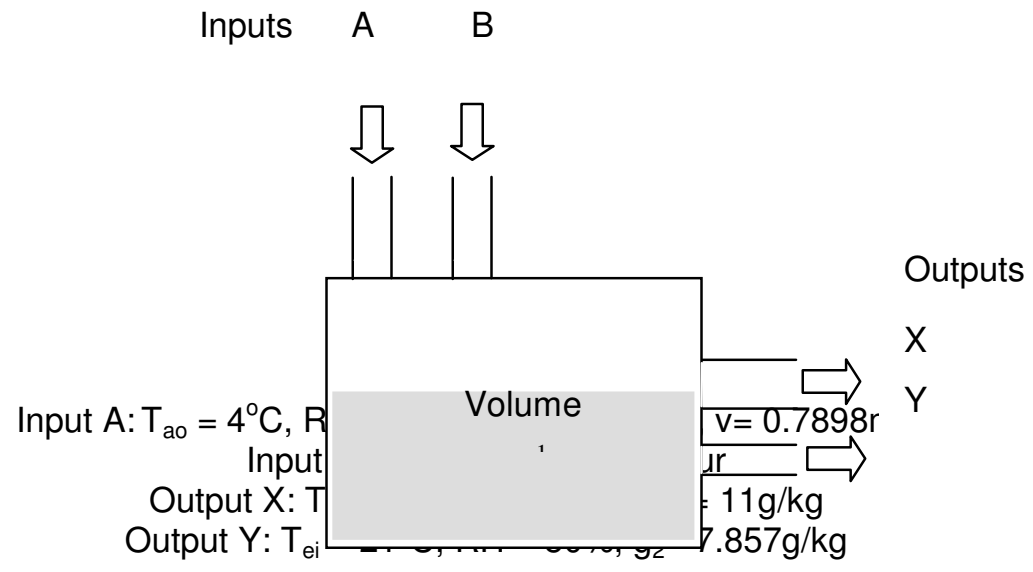

The volume flow rate is calculated for each model using the volume of the model and the associated air change rate. This is then used to calculate the mass flow rate of air, which when multiplied by the moisture difference between the internal and external air provides the mass flow rate of moisture. Moisture dissipation rates can then be determined assuming that all the moisture leaves the room. Three litres of water vapour was introduced into the model which equates to a pro rata $\left(\mathrm{m}^{2}\right)$ proportion of the average daily household production ${ }^{(3)}$.

$$
\begin{aligned}
\text { moisture difference } & =g_{1}-g_{2}[\mathrm{~kg} / \mathrm{kg} \text { day }] \\
\text { volume flow rate } & =\text { volumexair change rate }\left[\mathrm{m}^{3} / \mathrm{s}\right]
\end{aligned}
$$




$\begin{aligned} \text { mass flow rate of air } & =\frac{\text { volume flow rate }[\mathrm{kg} / \mathrm{s}]}{\mathrm{specific} \mathrm{volume}} \\ \text { mass flow of moisture } & =\text { moisture differencexmass flow rate }[\mathrm{kg} / \mathrm{s}] \\ \text { time to dissipate } 3 \text { litres of moisture } & =\frac{3 / \text { mass flow rate of moisture }[\mathrm{hrs}]}{3600}\end{aligned}$

\begin{tabular}{|c|c|c|}
\cline { 2 - 3 } \multicolumn{1}{c|}{} & \multicolumn{2}{c|}{ Time (hrs } \\
\cline { 2 - 3 } \multicolumn{1}{c|}{} & $@ 70 \% \mathrm{RH}$ & $@ 50 \% \mathrm{RH}$ \\
\hline 1890 model & 2.47 & 4.53 \\
\hline 1936 model & 4.93 & 8.98 \\
\hline 1950 model & 11.02 & 20.11 \\
\hline 1970 model & 11.12 & 20.25 \\
\hline 2000 model & 22.4 & 41.28 \\
\hline
\end{tabular}

Given that the air input has a relatively low mixing ratio it is predicted to take over 40 hours to reach the $50 \% \mathrm{RH}$ boundary condition in the 2000 model. It is thus more likely that relatively tight, energy efficient, modern dwellings will be subject to progressive and cumulative moisture build-ups during the winter months if windows remain closed. They are also likely to have water vapour burdens that maintain $\mathrm{RH}$ above the crude $50 \%$ threshold, allowing the establishment and proliferation of dust mite colonies. Furthermore, diurnal temperature variations - particularly in lightweight construction that has little thermal capacitance - will be greater, increasing relative humidity and condensation rates, which can be absorbed by carpets, bedding and soft furnishings. As ambient air in the warmer months - particularly along the western seaboard - is in the main higher than $7 \mathrm{~g} / \mathrm{kg}$ of dry air, there is little scope for reducing the internal humidity below dust mite viability levels. Winter ventilation rates are thus the crucial variable in inhibiting colony size and activity.

\section{$8 \quad$ Indoor humidity and the dust mite hypothesis}

Several epidemiological studies ${ }^{(4-6)}$ have identified the health implications of living in damp homes. Dampness has been strongly associated with respiratory disease and higher mite numbers. The 1996 Scottish House Condition Survey ${ }^{(1)}$ established that $25 \%$ of all dwellings suffer from problems of dampness and/or condensation. It is estimated $^{(7)}$ that around $80 \%$ of allergic asthmatics react to extracts of mite allergens. This indoor allergen exposure is important as contemporary leisure pursuits, provided by television and computers, have increased time spent indoors ${ }^{(8)}$. Evidence implicating the house dust mite as the prime causal factor, came from an investigation into the rise in asthma symptoms associated with mite colonisation in Papua New Guinea $^{(9)}$ where other causal factors associated with Western lifestyles were not present.

The ideal conditions for mites to proliferate is at a temperature of $25^{\circ} \mathrm{C}$ and a relative humidity of $80 \%{ }^{(10 \& 11)}$. A high humidity is very important to the survival of these creatures as most of their water is gained from the atmosphere by osmosis ${ }^{(10)}$. Under ideal conditions the life span of a mite is approximately two to three months ${ }^{(11)}$. Mite numbers vary seasonally, rising and falling in accordance with humidity cycles within the house ${ }^{(12 \& 13)}$. Where ventilation rates are low and average internal temperatures are 
above $20^{\circ} \mathrm{C}$, ambient humidity may play a reduced role, as domestic activities such as showering and internal clothes drying, could significantly increase the internal water vapour pressures and reduce the influence of external circadian variations. As the main food of mites is human skin, heavily used soft furnishings, provide a suitable environment for the development of mite colonies" ${ }^{(14 \& 15)}$. Skin scales absorb moisture from the atmosphere and are colonised by the fungus Aspergillus $S p .^{(16)}$. The yeast causes the scales of skin to swell moistening and softening them and reducing the fat content as an aid to digestion ${ }^{(17)}$. This adds further importance to the role of humidity in the lives of the house dust mite, as moulds generally require a relative humidity of $65 \%$ or greater ${ }^{(18 \& 19)}$. Such conditions can however exist in specific micro-climates even when the surrounding humidity is relatively low and dust mites have a range of survival techniques which can be deployed during periods of low humidity eg hibernation and compaction $^{(12)}$.

\section{Dust mite allergens sensitisation thresholds}

Tovey ${ }^{(20)}$ observed that individual mite faecal pellets contain very high concentrations of allergens, which can trigger reactions in susceptible individuals. During their active reproductive life, females were observed to produce (under laboratory conditions) 200 to 300 eggs ${ }^{(21)}$. As each dust mite can produce up to 60 times its own body weight in faecal pellets during its life-span ${ }^{(20)}$ it is thus possible for relatively small colonies to generate large reservoirs of allergenic micro-particles. As these allergens have been shown to be stable for at least 4 years ${ }^{(22)}$, the number of live mites at any given period may bear little correlation with the quantity of allergen present. The assay which identifies the allergen protein Der pl, can thus be used as a longitudinal marker to determine the history of dust mite activity at any given location. Any study designed to investigate the role of HDM on asthmatic patients must include a strategy to attack the existing reservoir of HDM allergenic proteins contained in the dust reservoirs.

11 Methods - An interventionist, double blind, placebo controlled protocol 68 volunteer asthmatics (43 public sector dwellings) in North Lanarkshire (UK) were recruited via the local schools ( $50<15$ years at the outset) and a range of remedial measures were applied to their dwellings to reduce allergen reservoirs and dust mite activity. The dwellings were typically four apartment semi-detached properties with gas fired central heating, urea-formaldehyde cavity insulation and PVCu double glazing (average NHER rating of 5.2). The dwellings were monitored for six months to establish baseline profiles before retro-fitting MHRV cartridge units (Baxi Clean Air Systems E100) in bedrooms and living rooms. The cohort was split into two active groups: AG2 ( $n=32)$, (steam cleaning of carpets, new bedding and active fans) and AG1 $(n=17)$, (steam cleaning of carpets and new bedding with placebo fans). A control group, $(n=19)$ received placebo steam cleaning and placebo fans. Dust samples were taken from living room carpets, bedroom carpets and beds on a 3 month cycle; temperature in living rooms and temperature and relative humidity in bedrooms were continuously monitored at 90 minute intervals; self-recorded peak flow readings were taken morning and night, and a face to face health questionnaire was completed every three months.

\section{Results}

12.1 Immunological assays of dust reservoirs $\left(0.5 \mathrm{~m}^{2}\right.$ sampled in the living room and asthmatic's bedroom - one minute vacuum time) were undertaken and this initial 
monitoring cycle confirmed that $59 \%$ of living room carpet dust samples, $75 \%$ of bedroom carpets and $78 \%$ of beds contained Der p/ ratios greater than the WHO sensitisation threshold of $2 \mathrm{ug} / \mathrm{g}$ of house dust. ${ }^{(12)}$ In addition to this, $25 \%$ of living room carpets, $50 \%$ of the bedroom carpets and $56 \%$ of the beds, were found to contain concentrations greater than the upper threshold of $10 \mathrm{ug} / \mathrm{g}$ of house dust (see fig. 1)

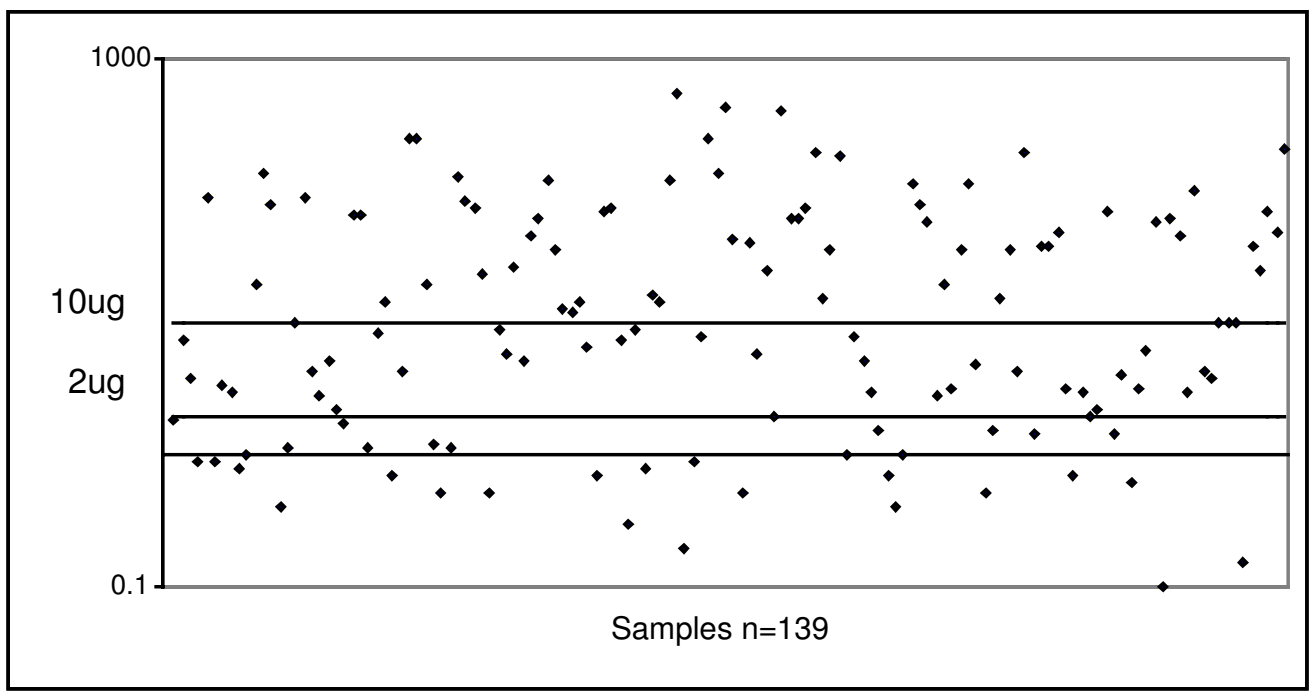

Fig. 1: Cycle I Log Ratio of Der pl/g of dust (carpets \& beds) - WHO levels $2 \& 10 \mathrm{ug} / \mathrm{g}$ When the initial dust sampling cycle was compared with the final cycle $(1 \& 8)$, the percentage above the WHO thresholds $(2 \& 10 \mathrm{ug} / \mathrm{g}$ dust) for all dust samples (carpets and beds) fell from $80 \%$ to $21 \%$ and $65 \%$ to $4 \%(n=78)$ respectively in active group II, from $61 \%$ to $41 \%$ and $34 \%$ to $4 \%$ in active group I $(n=31)$ and $65 \%$ to $15 \%$ in the control group ( $\mathrm{n}=39$ ). The total reduction for active group II was $96 \%$ (see fig 2 ).

Fig. 2: Log ratio Der p1/g house dust AG2 (all samples: cycles $1(\bullet) \& 8(\Delta)$ )

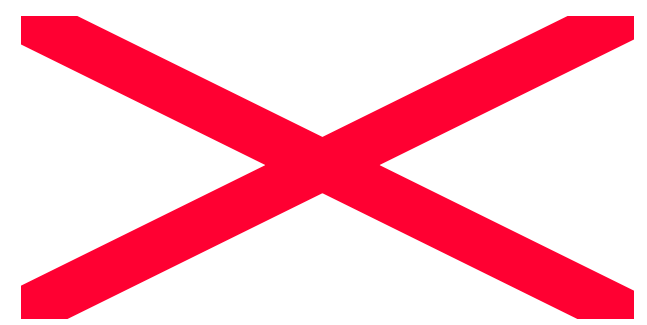


12.2 Relative humidity (bedrooms) - Readings taken during the first six winter months at 90 minute intervals in all bedrooms prior to intervention produced a mean $\mathrm{RH}$ of $55 \%$ (see fig 3). Even when the external moisture content is low - due to cold winter air temperatures - most of the bedrooms remained suitable for dust mite survival.

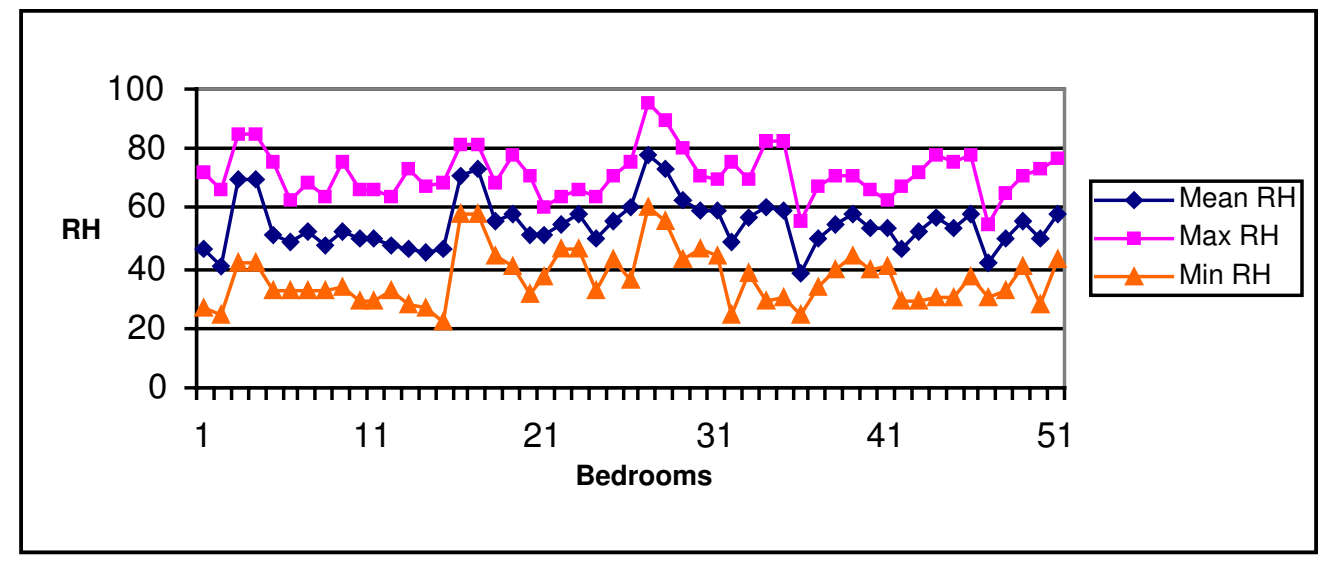

Figure 3 Mean $\mathrm{RH}$ and ranges (Oct $1998-$ Apr 1999)

12.3 Hygro-thermal monitoring - Humidity and temperature readings taken in bedrooms (every 90 minutes over a 22 month period), demonstrated a reduction in internal absolute water vapour pressures of $12 \%$ in the active group in comparison with the control groups (measured at the same time of year Jan-May 99 vs Jan-May 00). Figure 4 illustrates the hygro-thermal profile output for a dwelling in active group 2. A comparison of the 4 month winter periods before and after intervention (where ambient conditions were almost identical) shows a significant reduction in bedroom water vapour pressures. Mean internal dry bulb temperatures did not vary significantly before and after the intervention in the living rooms $\left(20.2\right.$ to $\left.20.6^{\circ} \mathrm{C}\right)$, however, the bedroom temperatures did fall by an average of $1.4^{\circ} \mathrm{C}\left(19.2\right.$ to $\left.17.8^{\circ} \mathrm{C}\right)$. This is a function of the increased background ventilation rates. 


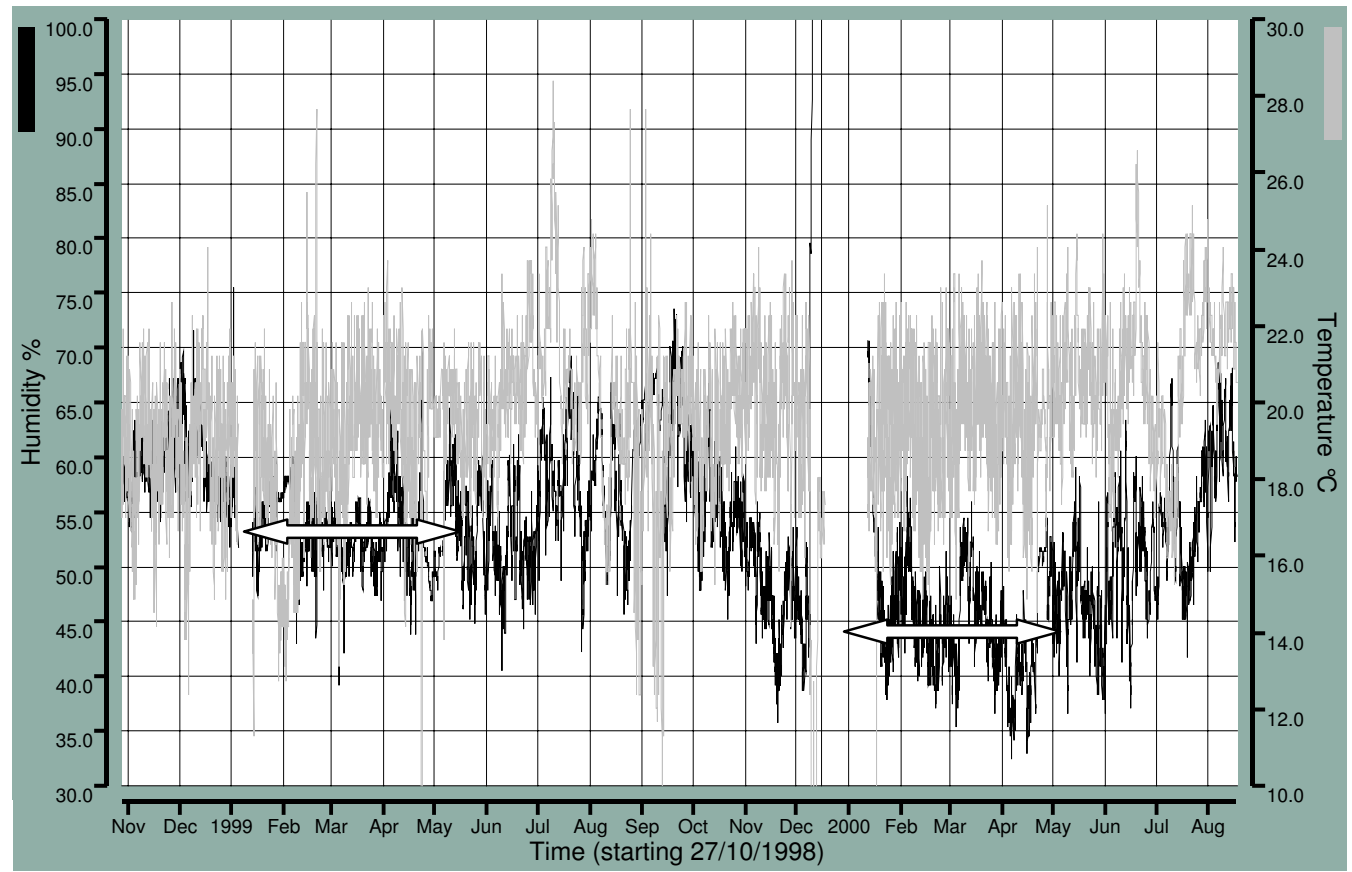

Fig. 4: Comparative before and after hygro-thermal profile of AG2 bedroom

12.4 Changes in Health Status - Peak flow readings taken before and after the interventions at the same time of year show some lung function improvements in all groups (see fig 5), however these figures have to be correlated with measured reductions in drug use, before any trends could be identified. Some of the increase will be due simply to child growth.

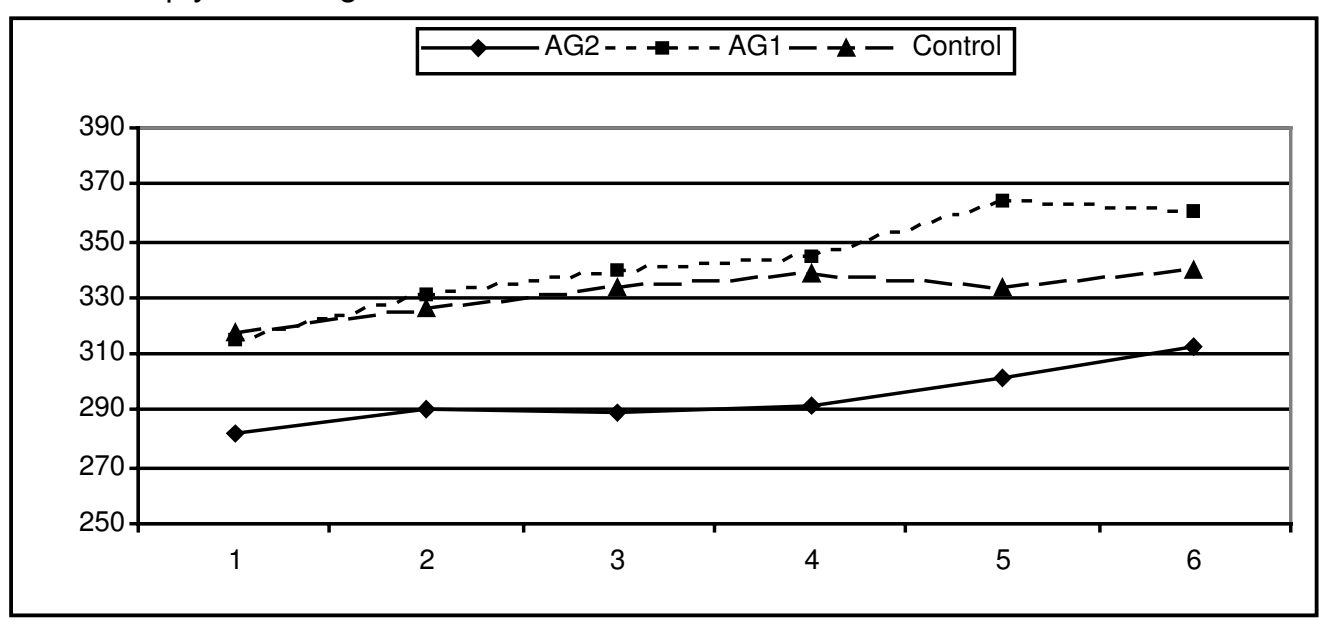

Fig. 5: Mean daily peak flow per group per cycle (litres/min mean am and pm readings)

12.5 Health status questionnaires - Face to face interviews using health questionnaires (shortened version of MacMaster ${ }^{(23)}$ ) were completed on a 3 monthly cycle by a 
contract researcher who was blind to the cohort groupings. The following are results from the two key questions introduced for the sixth data collection cycle ( 9 months after intervention).

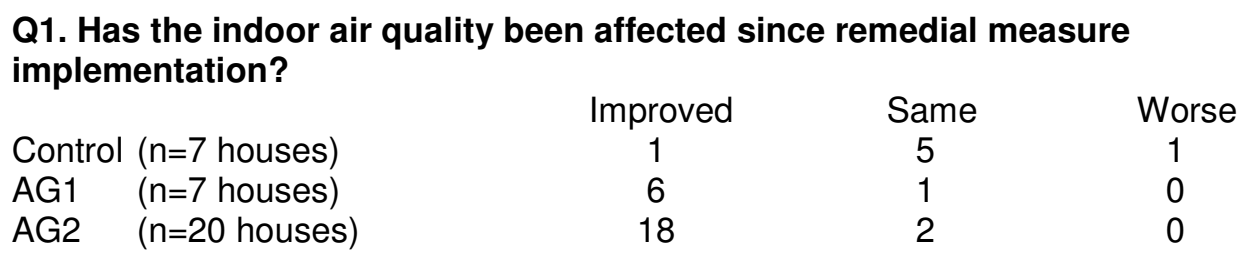

Q2. How has your asthma been affected since remedial measure
implementation?
$\begin{array}{llll}\text { Control }(n=10 \text { people }) & 1 & 7 & 2 \\ \text { AG1 } \quad(n=12 \text { people }) & 5 & 7 & 0 \\ \text { AG2 } \quad(n=32 \text { people }) & 26 & 6 & 0\end{array}$

From these figures we can conclude that there was a highly significant association between the extent of the intervention and perceived improvement in both air quality (Fisher's exact test $p=0.001$ ) and asthma (Fisher's exact test $p<0.0001$ ). Testing at the $5 \%$ level of significance, Q1 demonstrates that the three groups do not have the same probabilities for improvement. The active groups cannot be separated (at the $5 \%$ level) but have higher probability than the control group. The estimated probabilities are: $14 \%$ \& 89\%. Again, for Q2 the three groups are not the same. The Control group cannot be separated from AG1, with an estimated common probability of improvement of $27 \%$, whereas AG2 are $81 \%$.

\section{Discussion}

The level of $D e r p /$ identified in the existing dust reservoirs was considerable, with $59 \%$ of the living room carpet dust samples, $75 \%$ of the bedroom carpet dust samples and $78 \%$ of the bed surfaces over the WHO threshold for allergen sensitisation. Indeed $50 \%$ of the bedroom carpets and $56 \%$ of the bed surfaces contained more than $10 \mathrm{ug} / \mathrm{g}$ - the upper threshold known to be associated with severe allergic reactions. Since the amount of dust mite allergen seems to have an associated clinical risk, it is noteworthy that some exceptionally high concentrations were found with 18 samples above 100ug Der pl/g of dust, 9 of which were above 200ug Der pl/g of dust and 3 of which were above 400ug Der pl/g of dust. This pilot study has identified that seven out of ten cohort subjects were exposed to house dust mite allergen burdens above the WHO sensitisation thresholds. Although the cohort was not randomly selected - being volunteers - the house-types studied are typical of the Scottish public sector stock as a whole.

On average Der pl levels in AG II - which had the additional MHRV intervention - were reduced by over $96 \%$ (comparing cycles $1 \& 8$ - absolute weight of Der pl). The MHRV units also reduced the absolute humidity in the bedrooms, which may explain the reduction in re-colonisation rates. Although the participants were unaware that some fans were placebo units, which simply re-circulated the internal air, the health questionnaires demonstrated significant improvement in air quality and asthma. 
13.1 Confounding variables - There were however several confounding variables that may have influenced the overall result:

- As no pressure tests were undertaken the background air infiltration rates were unknown. Although the fan units provide circa 12 air changes per day to the bedrooms/living rooms, this has to be compared with the air infiltration characteristics of the dwelling.

- The placebo units were imperfect having filters that scoured the internal air of a significant amount of air-borne particulates.

- The age profile was heavily skewed $(65 \%$ of the cohort were under 16 at the outset of the study). Childhood asthma appears to be more capricious than the adult condition and their growth over the period would result in some increase in lung function.

- As no skin prick tests were undertaken to assess the cohort's sensitisation to HDM, the project could not differentiate between the health effects influenced by a reduction in airborne $\mathrm{Der} \mathrm{pl}$ and/or the overall improvement in indoor air quality by simple dilution of internal pollutants.

\section{Conclusions}

Changes in the design and use of the domestic environment over the latter part of the $20^{\text {th }}$ century are likely to have led to a significant increase in house dust mite concentrations in temperate/maritime influenced climatic regions. This in turn may be the prime causal factor influencing the rising incidence of asthmatic symptoms in children. Effective allergen denaturing/avoidance techniques such as steam cleaning and mattress encapsulation can significantly reduce the reservoir of allergenic protein available for inhalation. Mechanical heat recovery ventilation can reduce mixing ratios particularly during the winter months to a level below $7 \mathrm{~g} / \mathrm{kg}$ of dry air and $/$ or $50 \% \mathrm{RH}$, which will inhibit dust mite re-colonisation rates. This study has demonstrated that such a strategy is likely to result in an improvement in air quality and lung function. In addition to clinical improvement, significant cost savings from a reduction in drug use and primary/acute care services can accrue, rendering such an approach cost-effective both as a treatment and a preventative strategy. The implications for house design and ventilation rates are clear. As room volume drops and air tightness increases, complementary ventilation regimes will have to be incorporated if dust mites allergens are to be kept below sensitisation thresholds. From the simulations a rate of circa $0.9 \mathrm{ach}^{-1}$ appears to be the 'ball-park' figure (the simulated background rate with an additional $0.5 \mathrm{ach}^{-1}$ induced by MHRV). MHRV can also reduce the effective air change rate - in terms of energy losses - to around $0.3 \mathrm{ach}^{-1}$. Warm 'dry' healthy homes are now relatively easy to achieve.

\section{References}

1. Scottish Homes The 1996 Scottish House Conditions Survey
Edinburgh Scotland (1997)
2. CIBSE Guide Section B2 London (1986)
3. BRE Tackling condensation Garston Watford (1991)


4. Burr ML St Leger AS Yarnell JWG Wheezing, dampness \& coal fires Com.Med: 203 (1981)

5. Burr ML Miskelly FG Butland BK et al. Environmental factors and symptoms in infants at high risk of allergy $J$ Epidemiology 108:99-101 (1989)

6. Platt SD Martin CJ Hunt SM et al. Damp Housing, mould growth, and symptomatic health state BMJ 298 1673-1678 (1989)

7. Morrison-Smith Clinical significance of skin reactions to mite extracts in children with asthma BMJ 2:723-726 (1969)

8. Esmen NA. The status of indoor pollution. Environ Health Perspective 62:259-265 (1985)

9. Dowse GK, Turner KJ, Stewart GA, et al. The association between Dermatophagoides mites and the increasing prevalence of asthma in village communities within the Papau New Gineau Highlands. J Allergy Clin Immunol 75:75-83 (1985)

10. Hallas TE. The biology of mites. Allergy 11:6-9 (1990)

11. Wharton GW. House dust mites. J Med Ent 12 : 577-621 (1976)

12. Spieksma F Spieksma-Boezeman M The mite fauna of house dust with reference to the house-dust mite Dermataphogoides pteronyssinus.

Acarologia, 11:226-241 (1967)

13. Platts-Mills TAE de Weck AL Dust mite allergens and asthma - a worldwide problem J. Allergy and Clinical Immunology 83:416-427 (1989)

14. Sesay HR Dobson RM Studies on the mite fauna of house dust in Scotland with special reference to that of bedding Acarologia 14:384 (1972)

15. Van Bronswijk JEMH Dermataphogoides pteronyssinus (Troussart 1897) in mattress and floor dust in a temperate climate (Acari: Pyroglyphidae). J Med Ent 1 63-70 (1973)

16. Douglas AE Hart BJ The significance of the fungus Aspergillus penicilloides to the house dust mite Dermatophagoides pteronyssinus. Symbiosis 7:105-117 (1989)

17. Whitrow $D$ Pycock Rhouse Dust Mites: How they affect asthma, eczema and other allergies. Elliot Right Way England (1993)

18. Gravesen S Fungi as a cause of allergic disease Allergy 34 135-154 (1979)

19. Hart BJ Whitehead L Ecology of house dust mites in Oxfordshire Clin Exp Allergy 20:203-209 (1990)

20. Tovey ER Chapman MD Wells $\mathrm{CW}$ et al. The distribution of dust mite allergen in the houses of patients with asthma. Am Rev Repsir Dis 124:630-635 (1981)

21. Furumizo RT The biology and ecology of the house dust mite Dermatophagoides farinae PhD Dissertation Univ. of California (1973)

22. Kort HSM Kneist FM Four-year stability of Der $p /$ in house dust under simulated domestic conditions in vitro Allergy 49 131-133 (1994)

23. McMaster University Asthma quality of life questionnaire. Dept of Clinical Epidemiology and Biostatistics, McMaster University, Ontario, Canada (1992)

The authors would like to acknowledge the financial support of the University of Strathclyde, Energy Action Scotland, EAGA Charitable Trust, North Lanarkshire Council, Scottish Power and Baxi Clean Air Systems Ltd. 